\title{
EVALUASI DAN PENANGANAN JEMBATAN DI PULAU NIAS PROVINSI SUMATERA UTARA DENGAN METODE BRIDGE MANAGEMENT SYSTEM
}

\author{
Sumargo $^{1}$, Rachmat Hakiki ${ }^{2}$, Reni Raafidiani ${ }^{3}$ \\ ${ }^{1}$ Dosen Jurusan Teknik Sipil, Universitas Jendral Ahmad Yani (UNJANI), Cimahi \\ E-mail:smg.7ph1@gmail.com \\ ${ }_{2}^{2}$ Program Studi Magister Terapan Rekayasa Infrastruktur, Politeknik Negeri Bandung, Bandung \\ E-mail : rachmathakiki@gmail.com \\ ${ }^{3}$ Program Studi Konstruksi Bangunan, Politeknik TEDC Bandung, Cimahi \\ E-mail : reniraaf@poltektedc.ac.id.
}

\begin{abstract}
ABSTRAK
Suatu pemeliharaan jembatan didahului adanya kegiatan inspeksi kondisi dengan dilakukan penilaian terhadap kondisi jembatan di lapangan berdasarkan pada standar acuan dari Bridge Management System 1993. Tujuan dari penelitian ini adalah untuk mengevaluasi kondisi jembatan dan untuk mendapatkan tindakan perbaikan atau penanganan yang tepat. Pada penelitian ini dilakukan pada 10 jembatan di pulau Nias provinsi Sumatera Utara yang merupakan ruas jalan nasional. Dengan melakukan penilaian kondisi jembatan berdasarkan tata cara pemeriksaan kondisi jembatan secara visual detail, dengan menggunakan formulir pemeriksaan jembatan. Pemeriksaan visual detail kondisi jembatan meliputi bangunan atas, bangunan bawah, bangunan pelengkap, dan daerah aliran sungai. Pencatatan khusus meliputi kode elemen, jenis kerusakan, dan dilengkapi foto, sketsa kerusakan beserta lokasi kerusakannya, dan jumlah volume kerusakannya. Pemeriksaan daerah aliran sungai dengan menggunakan foto udara, dengan cakupan pengambilan kondisi aliran sungai yaitu $\pm 500 \mathrm{~m}$ arah hulu dan hilir jembatan yang kemudian dilakukan penyusunan konsep desain dan gambar konsep desain penanganan jembatan. Nilai kondisi dari 10 jembatan menggunakan standar BMS yaitu: 1 jembatan kondisi runtuh, 5 jembatan kondisi kritis, 2 jembatan kondisi rusak berat, 1 jembatan kondisi rusak ringan dan 1 jembatan kondisi baik. Dari penilaian beberapa jembatan di pulau Nias provinsi Sumatera Utara memperoleh nilai dari kondisi masing-masing Jembatan Idano Gido Sebua, Jembatan Idano O'ou, Jembatan Idano Hili Geho, Jembatan Idano Gewa, Jembatan Idano Mezawa adalah jembatan paling kritis yang memiliki nilai kritis. Sementara Jembatan Idano Matuho memiliki nilai kondisi rusak berat. Karena metode yang digunakan pada inspeksi kondisi jembatan secara visual maka perlunya dilakukan pemeriksaan lebih lanjut setelah dilakukan pemeriksaan dan penilaian kondisi jembatan agar dapat mengetahui kerusakan pada komponen bagian dalam jembatan.
\end{abstract}

Kata Kunci : Bridge Management System, Inspeksi Jembatan, Nias

\section{ABSTRACT}

A bridge maintenance is preceded by a condition inspection activity by conducting an assessment of the condition of the bridge in the field based on the reference standards of the Bridge Management System (BMS) 1993. The purpose of this study is to evaluate the condition of the bridge and to obtain corrective action or appropriate handling. This research was conducted on 10 bridges on Nias island, North Sumatra province, which are national roads. By conducting an assessment of the condition of the bridge based on the procedure for inspecting the condition of the bridge visually in detail, using the bridge inspection form. Detailed visual inspection of bridge conditions including superstructure, substructure, complementary structures, and watersheds. Special records include the element code, type of damage, and include a photo, a sketch of the damage and the location of the damage, and the volume of the damage. Examination of the watershed using aerial photographs, with the coverage of taking river flow conditions, namely $\pm 500 \mathrm{~m}$ in the upstream and downstream direction of the bridge, which is then carried out by compiling the design concept and drawing the bridge handling design concept. The condition value of 10 bridges uses the BMS standard, namely: 1 bridge in a collapsed condition, 5 bridges in critical condition, 2 bridges in severely damaged condition, 1 bridge in lightly damaged condition and 1 bridge in good condition. From the assessment of several bridges on Nias island, North Sumatra province, the values of the conditions of each of the Idano Gido Sebua Bridge, Idano O'ou Bridge, Idano Hili Geho Bridge, Idano Gewa Bridge, Idano Mezawa Bridge are the most critical bridges that have critical values. Meanwhile, the Idano Matuho Bridge has a severely damaged condition. Due to the method used in visual inspection of bridge conditions, further inspection is necessary after inspection and assessment of the condition of the bridge in order to find out the damage to the inner components of the bridge.

Keywords: Bridge Management System, Bridge Inspection, Nias 


\section{PENDAHULUAN}

Inspeksi kondisi jembatan merupakan usaha pemeliharaan jembatan untuk mempertahankan umur jembatan agar mencegah terjadinya kerusakan struktur jembatan yang berkelanjutan karena akibat umur yang akan mengalami degradasi, baik disebabkan karena durabilitas material jembatan, kondisi lingkungan maupun akibat bencana alam yang dapat mengurangi kemampuan layan jembatan tersebut. Kegiatan pemeriksaan kondisi jembatan wilayah jalan nasional merupakan bagian dari kegiatan layanan teknis dan alih teknologi sistem inspeksi jembatan, yang dikhususkan untuk melakukan pengambilan data kondisi dengan menggunakan standar acuan Bridge Management System (BMS) 1992. Dari data tersebut dapat menentukan kriteria untuk nilai kondisi jembatan di wilayah jalan nasional. Data kondisi jembatan akan dilaporkan dan dapat digunakan untuk merencanakan suatu program pemeliharaan, rehabilitasi, perkuatan penggantian jembatan dan juga sebagai data pembanding untuk waktu yang akan datang. Dengan adanya kegiatan inspeksi ini diharapkan dapat memberikan rekomendasi secara teknis terkait dengan program penanganan jembatan yang akan dilakukan di setiap Balai Besar Pelaksanaan Jalan Nasional. Agar terhindar dari keruntuhan jembatan maka diperlukan inspeksi kondisi dengan menilai kondisi jembatan sehingga dapat dilakukan tindakan perbaikan atau penanganan lebih lanjut. Untuk menentukan manajemen pemeliharaan yang tepat pada jembatan maka perlunya dilakukan inspeksi kondisi dan penilaian yang akurat terhadap struktur jembatan ${ }^{[1]}$. Dalam inspeksi ini dilakukan penilaian kondisi pada 10 (sepuluh) jembatan di pulau Nias provinsi Sumatera Utara dengan menggunakan metode Bridge Management System (BMS). Menilai kondisi jembatan di lapangan berdasarkan standar acuan dari Bridge Management System (BMS) 1992, mulai dari bangunan atas jembatan, bangunan bawah jembatan, bangunan pelengkap, dan daerah aliran sungai sekitar jembatan serta menyusun konsep dan gambar desain penanganan jembatan. Tujuan dari penelitian ini adalah untuk mengevaluasi kondisi jembatan dan untuk mendapatkan tindakan perbaikan atau penanganan yang tepat

\section{TINJAUAN PUSTAKA}

Direktorat Jenderal Bina Marga pada tahun 1992 mengembangkan metode Bridge Management System (BMS) untuk pelaksanaan manajemen jembatan pada jalan nasional dan provinsi. Tujuan rencana dan program dalam Bridge Management System (BMS) yaitu mengidentifikasi jembatan yang tidak memenuhi standar baik standar kondisi dan lalu lintas, untuk menentukan strategi penanganan jangka panjang yang dapat menghasilkan nilai ekonomi yang terbaik sehingga menjamin semua penanganan dapat terpantau dan database jembatan selalu dalam keadaan terbaru. Pada tahap inspeksi elemen jembatan menggunakan Bridge Management System (BMS) terdapat 5 level penilaian yang masing-masing memiliki kode, dimana kode ini terdiri dari kode kerusakan material dan elemen ${ }^{[1]}$. Komponen kegiatan yang terdapat pada Bridge Management System (BMS) yaitu inspeksi jembatan, rencana dan pemrograman, perencanaan teknik pelaksanaan, pengawasan dan pemeliharaan jembatan ${ }^{[2]}$. Terdapat kelemahan dan kekurangan pada penilaian kondisi dengan Brigde Management System (BMS) 1993 Bina Marga, yaitu belum adanya metode penilaian kondisi pada jembatan beton prategang. Penilaian kondisi jembatan prategang hanya dilakukan secara visual yaitu penilaian kondisi terhadap beberapa aspek keamanan struktur dan aspek kenyamanan lalu lintas sehingga tidak dapat memprediksi kerusakan-kerusakan pada komponen-komponen beton di bagian dalam ${ }^{[3]}$. Dari data hasil nilai kondisi jembatan maka dapat dilakukan proses penyaringan dari database terhadap jembatan yang memerlukan suatu penanganan, penggantian dan rehabilitasi pada jembatan dengan memanfaatkan Sistem Informasi Manajemen Jembatan (IBMS), BMS juga dapat digunakan untuk memutuskan perawatan yang diperlukan untuk memelihara jembatan dalam keadaan tertentu. Selanjutnya BMS Berbasis Komputer yang dikombinasikan dengan sistem informasi terintegrasi dapat menunjukkan kepada kita skala prioritas untuk mengelola pemeliharaan jembatan. Namun penilaian visual jembatan merupakan langkah penting untuk mengevaluasi kondisi umum jembatan ${ }^{[4]}$. Penilaian kondisi jembatan rangka baja setelah di lakukan penilaian kondisi melalui pemeriksaan secara inventaris maka jembatan rangka baja dapat di ambil peringkat kondisi dari elemen penting jembatan yang meliputi bangunan atas, sistem lantai, sandaran, fondasi, abutmen/pilar dan daerah aliran sungai apabila memerlukan pemeliharaan rutin penerapannya terdapat dalam metode Brigde Management System (BMS) 1993 ${ }^{[5]}$. Visual Inspection of Bridge atau INVI J merupakan perangkat lunak sebuah aplikasi mobile dan aplikasi berbasis web yang mana inspeksi jembatan yang memadukan metode pemeriksaan dengan cara visual dan instrumentasi yang dikembangkan oleh Badan Penelitian dan Pengembangan Jalan dan Jembatan dimana aplikasi Inspeksi Jembatan ini merupakan bagian dari sistem informasi manajemen jembatan terpadu ${ }^{[6]}$. Bridge Management System (BMS) adalah sistem komputer terintegrasi untuk memberikan dukungan keputusan selama fase desain, konstruksi, operasi, dan pemeliharaan. BMS dapat meningkatkan efisiensi manajemen dan mengurangi biaya yang berlebihan dalam menangani masalah manajemen infrastruktur ${ }^{[7]}$. Banyak BMS yang telah dikembangkan, dan hasil praktis yang cukup baik telah dicapai, seperti BMS berbasis GIS ${ }^{[8]}$, BMS berbasis data inspeksi visual ${ }^{[9]}$ dan BMS berbasis consecutive condition assessment ${ }^{[10]}$. Namun, pada tahap sekarang orang-orang masih fokus pada konstruksi tetapi bukan pemeliharaan. Selama pengoperasian jembatan dalam waktu yang lama, struktur jembatan mengalami tingkat kerusakan yang berbeda yang disebabkan oleh beban dan pengaruh lingkungan, yang kemudian mengurangi keandalan struktur dan memperpendek masa pakai yang diharapkan. Misalnya, karat yang parah dapat mengakibatkan runtuhnya jembatan, seperti hancurnya jembatan gerbang selatan Yi Bin di Cina. Banyak juga kasus cacat jembatan atau bahkan kecelakaan kehancuran yang serupa dan penyebab utamanya adalah kurangnya perawatan ${ }^{[11]}[12]$. 


\section{METODE PENELITIAN}

Melakukan penilaian kondisi jembatan berdasarkan tata cara pemeriksaan kondisi jembatan secara visual detail, dengan menggunakan formulir pemeriksaan jembatan. Pemeriksaan visual detail kondisi jembatan meliputi bangunan atas, bangunan bawah, bangunan pelengkap, dan daerah aliran sungai. Pencatatan khusus meliputi kode elemen, jenis kerusakan, dan dilengkapi foto, sketsa kerusakan beserta lokasi kerusakannya, dan jumlah volume kerusakannya. Pemeriksaan daerah aliran sungai dengan menggunakan foto udara, dengan cakupan pengambilan kondisi aliran sungai yaitu $\pm 500 \mathrm{~m}$ arah hulu dan hilir jembatan dan kemudian dilakukan penyusunan konsep desain penanganan jembatan di ruas jalan nasional dan penyusunan gambar konsep desain penanganan jembatan di ruas jalan nasional. Berdasarkan data Laporan Umum Data Jembatan Direktorat Jenderal Bina Marga provinsi Sumatera Utara berikut telah dipilih beberapa jembatan yang perlu dilakukan pemeriksaan atau memiliki peluang untuk dilakukan pemeriksaan sehingga dapat menjadi prioritas untuk mendapat rekomendasi perbaikan struktur jembatan. Pemeriksaan dilakukan pada jembatan yang ditandai di peta pada Gambar 1 dan dapat terlihat pada Tabel 1 data 10 jembatan yang akan diperiksa yang terdapat di pulau Nias provinsi Sumatera Utara berikut

Tabel 1. Data Jembatan yang Diperiksa di Provinsi Sumatera Utara (Pulau Nias)

\begin{tabular}{|c|c|c|c|c|c|}
\hline No & $\underset{\text { Jembatan }}{\text { Nama }}$ & $\begin{array}{c}\text { Panjan } \\
\text { g } \\
(\mathrm{m})\end{array}$ & $\begin{array}{c}\text { Jumla } \\
\text { h } \\
\text { Bentan } \\
\text { g } \\
\end{array}$ & $\begin{array}{l}\text { Leba } \\
\text { r } \\
(\mathbf{m})\end{array}$ & $\begin{array}{c}\text { Tipe } \\
\text { Bangun } \\
\text { an Atas }\end{array}$ \\
\hline 1 & $\begin{array}{l}\text { Idano Gido } \\
\text { Sebua }\end{array}$ & 50,70 & 3 & 6,3 & GTI \\
\hline 2 & $\begin{array}{l}\text { Idano } \\
\text { Matuho }\end{array}$ & 12,60 & 1 & 6,5 & GTI \\
\hline 3 & Idano O’ou & 187,90 & 5 & 3,0 & SBW \\
\hline 4 & Idano La'uri & 60,40 & 1 & 6,2 & RBA \\
\hline 5 & $\begin{array}{l}\text { Idano Hili } \\
\text { Geho }\end{array}$ & 26,00 & 1 & 6,2 & GTI \\
\hline 6 & $\begin{array}{l}\text { Idano } \\
\text { Bowongahon } \\
\text { o }\end{array}$ & 25,80 & 1 & 6,2 & GTI \\
\hline 7 & Idano Gewa & 30,80 & 1 & 4,3 & $\mathrm{RBP}$ \\
\hline 8 & Idano Susua & 60,30 & 1 & 6,1 & RBR \\
\hline 9 & $\begin{array}{l}\text { Idano } \\
\text { Mezawa }\end{array}$ & 45,30 & 1 & 6,0 & RBR \\
\hline 10 & $\begin{array}{l}\text { Idano } \\
\text { Mo'awu }\end{array}$ & 30,50 & 1 & 7,0 & RBR \\
\hline
\end{tabular}

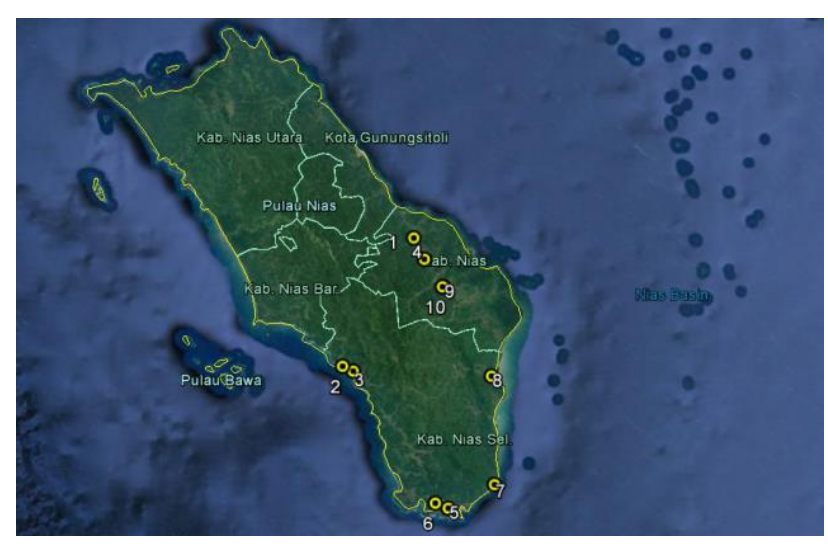

Gambar 1. Peta Lokasi Pemeriksaan Kondisi Jembatan Pulau Nias

Keterangan:

GTI = Gelagar Beton Indonesia

SBW = Jembatan Type Bailey

RBA $\quad=$ Rangka Baja Australia

RBP = Rangka Baja Australia (Semi Permanen)

RBR = Rangka Baja Austrian

Jembatan yang menjadi prioritas perbaikan adalah jembatan dengan nilai kondisi yang besar. Pada Tabel 2 adalah skala nilai kondisi jembatan berdasarkan kondisi fisik dan strukturnya.

Tabel 2. Nilai Kondisi Jembatan

\begin{tabular}{cl}
\hline $\begin{array}{c}\text { Nilai } \\
\text { Kondisi }\end{array}$ & \multicolumn{1}{c}{ Kondisi Jembatan } \\
\hline 0 & Jembatan baru dan tanpa kerusakan \\
1 & Kerusakan kecil \\
2 & Kerusakan yang memerlukan pemantauan atau \\
3 & pemeliharaan di waktu mendatang \\
4 & Kerusakan yang memerlukan tindakan secepatnya \\
5 & Elemen jembatan tidak berfungsi lagi \\
\hline
\end{tabular}




\section{HASIL DAN PEMBAHASAN}

Berikut adalah studi kasus yang dilakukan oleh peneliti pada jembatan di pulau Nias provinsi Sumatera Utara. Studi kasus yang dilakukan peneliti adalah melakukan penilaian langsung ke lokasi jembatan tersebut dimana berdasarkan proses inspeksi kondisi jembatan ditemukan beberapa kerusakan dan penanganan pada kerusakan sebagai berikut:

\subsection{Inspeksi Kondisi Jembatan \\ 4.1.1 Inspeksi Lantai Jembatan}

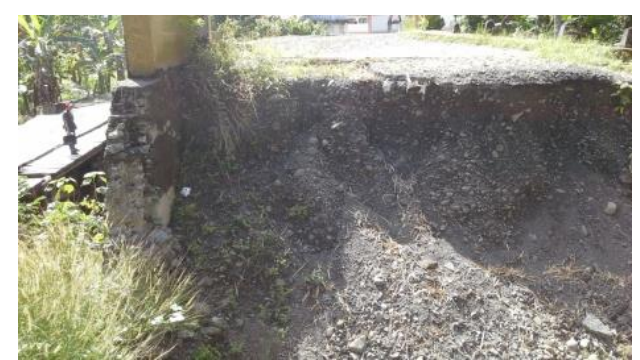

Gambar 2. Amblasnya Pelat dan Timbunan Pendekat Jembatan Idano Matuho

Kerusakan pada lapisan perkerasan terjadi karena sebagian timbunan jalan pendekat hilang atau mengalami penurunan (amblas) sehingga jembatan tidak berfungsi lagi diperlihatkan pada Gambar 2. Kerusakan tersebut termasuk ke dalam kerusakan berat karena rusaknya elemen struktural.

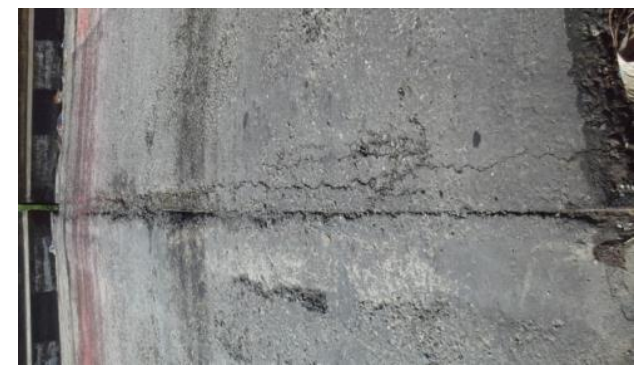

Gambar 3. Retak Aspal Akibat Pergerakan Sambungan pada Jembatan Idano Gido Sebua

Kerusakan retak aspal teridentifikasi akibat adanya retakan pada lapis permukaan yang disebabkan akibat adanya pergerakan dari sambungan lantai seperti yang terlihat pada Gambar 3. Kerusakan tersebut termasuk ke dalam rusak berat dengan retak $>15 \mathrm{~mm}$.

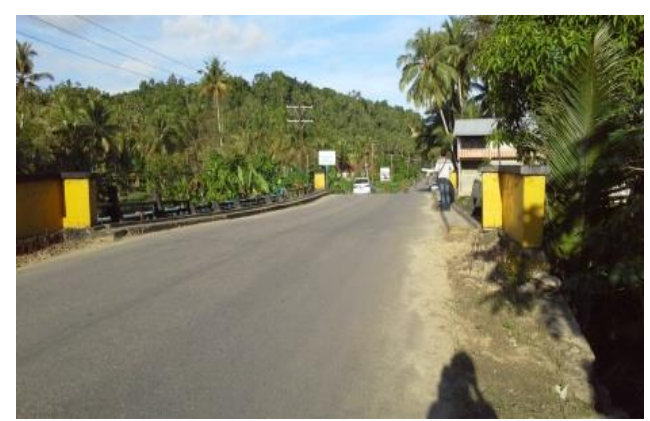

Gambar 4. Lendutan Pelat Lantai pada Jembatan Idano Hili Geho

Pada Gambar 4 terlihat terjadi lendutan di pelat lantai akibat adanya kerusakan pada balok yang menyebabkan kekakuan stukturnya menurun dan akhirnya melendut. Lendutan pada balok membuat permukaan pelat lantai ikut melendut dan perlu dilakukan rehabilitasi jembatan karena bangunan sudah melendut dan tulangan sudah banyak yang hilang. Kerusakan tersebut termasuk kedalam kerusakan berat karena kerusakan pada pelat lantai $>1: 600$.

\subsubsection{Inspeksi Bangunan Atas Jembatan}

Pada Gambar 5 terlihat kerusakan pada gelagar jembatan yang disebabkan karena fondasi runtuh/kegagalan fondasi sehingga gelagar miring akibat mengikuti pergerakan abutment yang berdeformasi sebagian. Kerusakan tersebut termasuk ke dalam kerusakan berat karena rusaknya elemen struktural. 


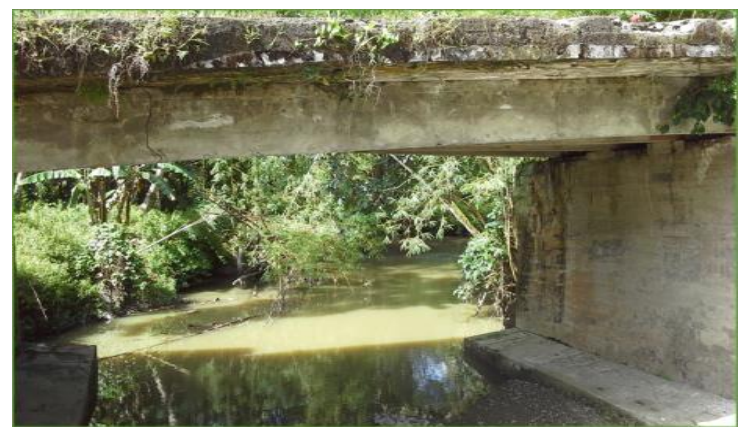

Gambar 5. Gelagar Jembatan Idano Matuho Miring

Pada Gambar 6 terlihat bahwa Jembatan Idano Matuho tidak lagi memiliki tiang sandaran dan sandaran horizontalnya. Pada kondisi awal, jembatan memiliki 6 tiang sandaran dan 5 segmen dan 2 baris sandaran horizontal. Kerusakan termasuk kerusakan ringan karena rusaknya elemen non struktural sandaran horizontal dan atau tiang sandaran yang mengalami kerusakan dan atau hilang perlu dilakukan penggantian item tersebut dengan item yang baru.

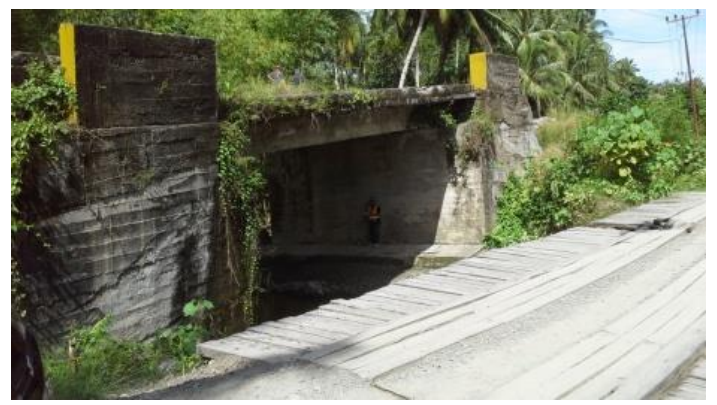

Gambar 6. Bagian Tiang Sandaran Jembatan Idano Matuho yang Rusak atau Hilang

Pada Gambar 7 terlihat bahwa terjadi kerusakan pada seluruh gelagar (4 buah) dan diafragma pada abutment dengan kerusakan variatif yaitu keropos beton akibat buruknya pekerjaan pembetonan, retak beton, dan tulangan yang mencuat keluar. Perlu rehabilitasi jembatan karena bangunan sudah melendut dan tulangan sudah banyak hilang dan termasuk kerusakan berat.

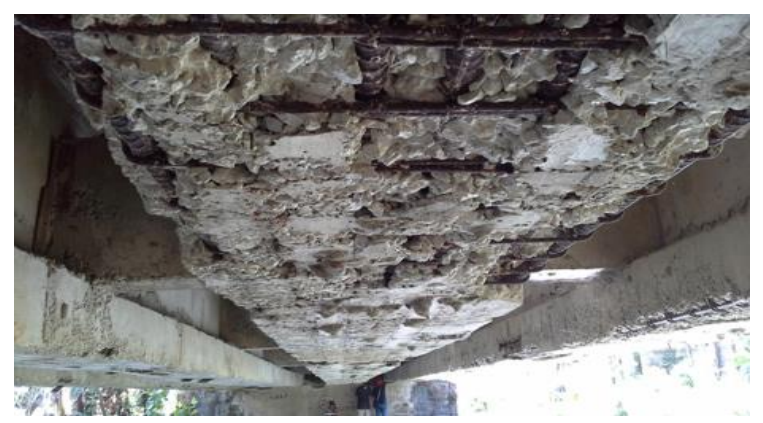

Gambar 7. Kerontokan Beton, Beton Keropos, Kualitas yang Buruk Jembatan Idano Bawonahono

Pada Gambar 8 terlihat kerusakan pada ikatan angin bawah di segmen ke-1 dan ke-4 dari sisi Gunung Sitoli, dimana kerusakan diakibatkan oleh korosi / karat yang berlebih sehingga membuat kekuatan batang berkurang dan menyebabkan perubahan bentuk hingga patah atau kehilangan bagian dari elemennya.

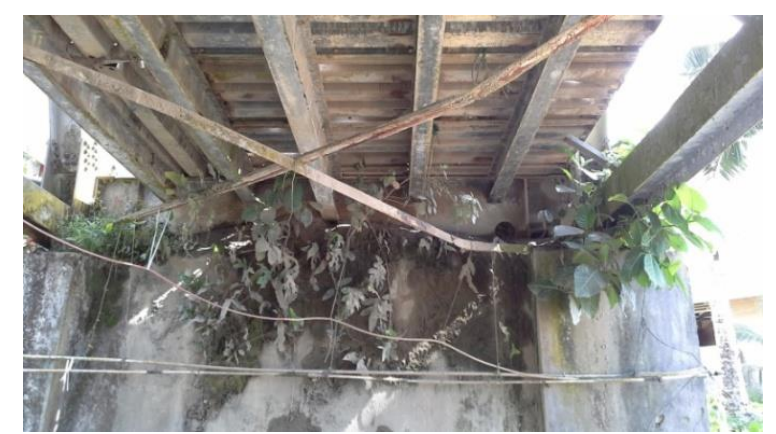

Gambar 8. Korosi pada Komponen Jembatan Idano Gewa 


\subsubsection{Inspeksi Bangunan Bawah Jembatan}

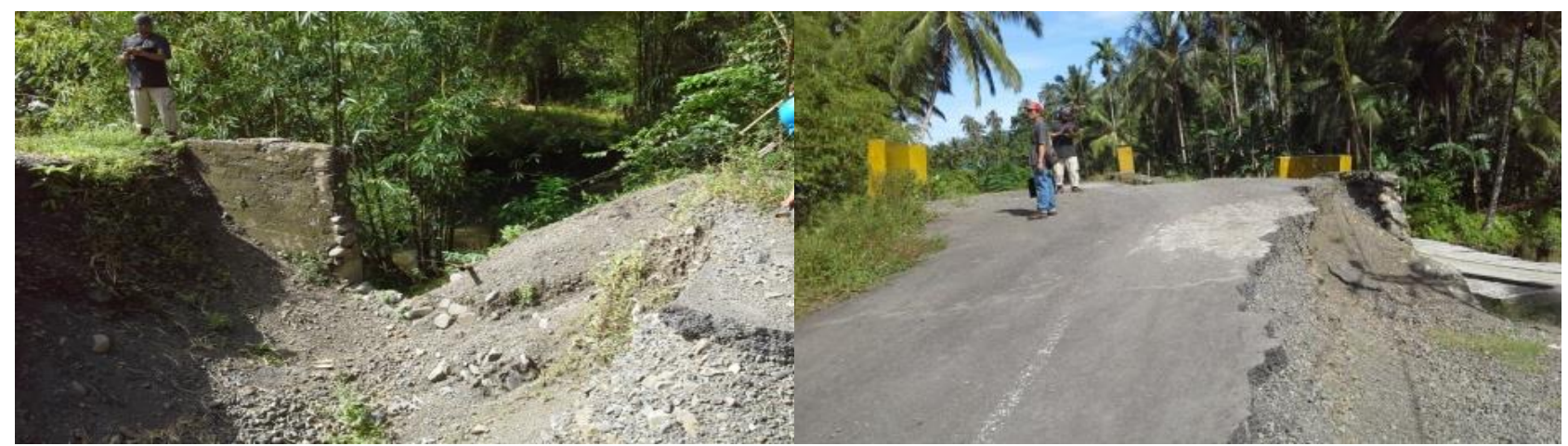

Gambar 9. Oprit di Sisi Gunung Sitoli Amblas di Seluruh Penampang Melintangnya dan Oprit di Sisi Lolowau Amblas di Sebagian Penampang Melintangnya

Pada Gambar 9 terlihat adanya penurunan pada tanah timbunan jalan pendekat hingga amblasnya permukaan di kedua sisi abutment jembatan Idano Matuho. Kerusakan tersebut termasuk ke dalam kerusakan berat karena hilangnya $>10 \%$ elemen jembatan.

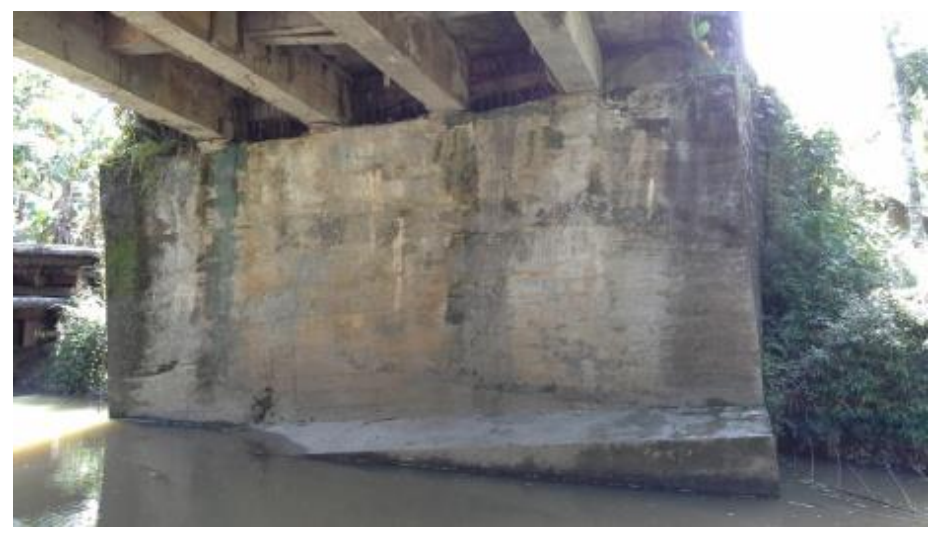

Gambar 10. Penurunan Abutment Jembatan Idano Matuho

Pada Gambar 10 terlihat abutment di sisi Loloao mengalami deformasi akibat adanya penurunan pada tanah dasar. Kerusakan tersebut digolongkan kerusakan berat karena penurunan $>50 \mathrm{~mm}$.

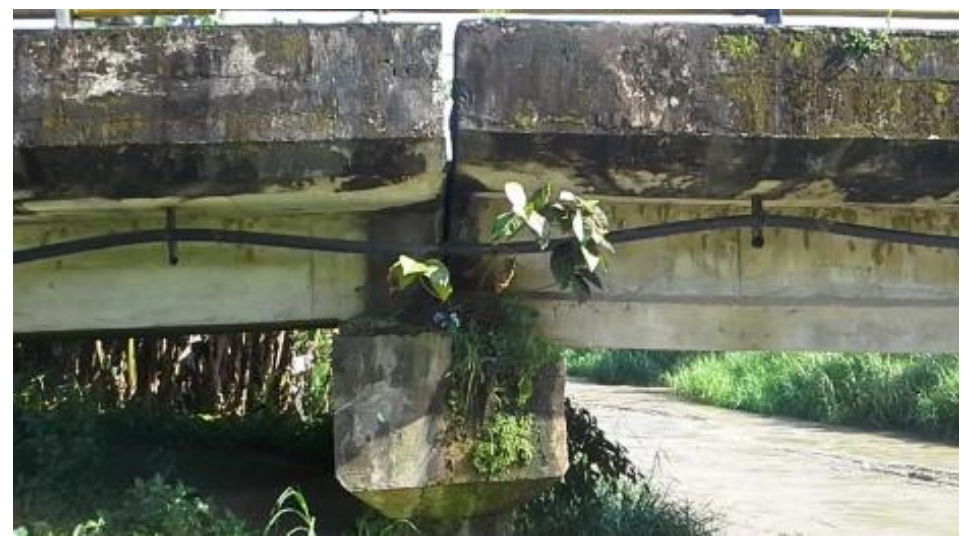

Gambar 11. Pergeseran lateral pada Jembatan Idano Gido

Terlihat pada Gambar 11 Jembatan Idano Gido Sebua yang terdiri dari 3 segmen dimana pada segmen tengah mengalami pergeseran lateral dan vertikal akibat gempa 24 Desember 2004. Tetapi bisa juga terjadi gempa menyebabkan gerakan lateral yang mendorong jembatan dari arah Teluk Dalam (segmen 3) lalu mendorong segmen tengah, berlanjut ke segmen pertama (sisi Gunung Sitoli) dan mendorong abutment. Antara oprit dan jembatan segmen pertama dan ketiga dari sisi Gunung Sitoli mengalami perbedaan tinggi sehingga saat kendaraan melewati oprit menuju jembatan ada lompatan dan menimbulkan impact pada lantai jembatan. 


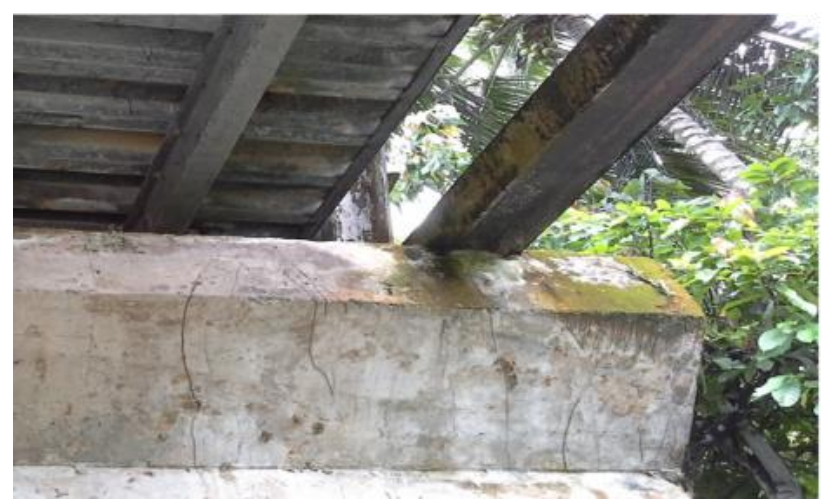

Gambar 12. Kepala Jembatan Idano La'uri atau Pilar Bergerak

Pada Gambar 12 terlihat abutmen sudah miring terjungkit pada sisi Teluk Dalam (A2). Abutment terjungkit menyebabkan batang tepi bawah sudah menumpu pada abutmen. Harus dilakukan pemeriksaan khusus monitoring dan segera lakukan tindakan darurat. Perlu perlindungan terhadap abutment agar tidak terjungkit lebih jauh serta perlu dilakukannya pengamatan.

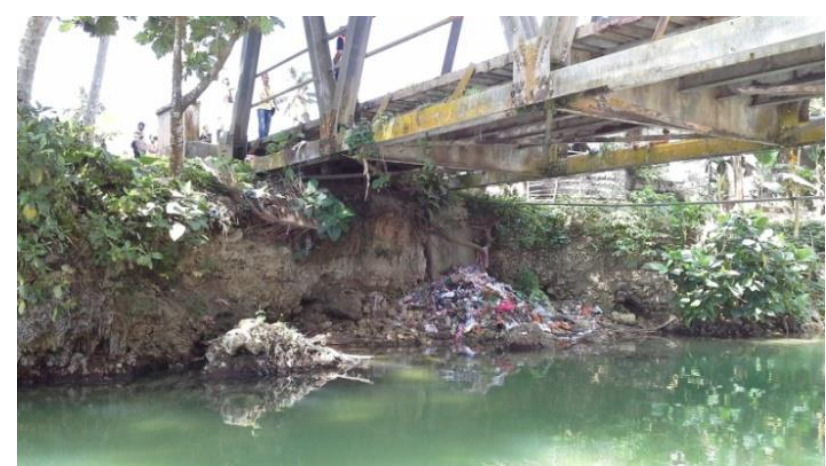

Gambar 13. Pengerusan pada Abutment Jembatan Idano Gewa

Kerusakan abutmen jembatan yang disebabkan penggerusan pada kedua sisinya dan pada kerusakan tersebut termasuk kerusakan berat karena terjadi pengikisan dasar sungai yang terlihat pada Gambar 13 Perlunya penambahan masa beton dan perlindungan abutmen berupa pemasangan bronjong pada kedua sisi sungai sepanjang 50 meter pada hulu dan hilir jembatan.

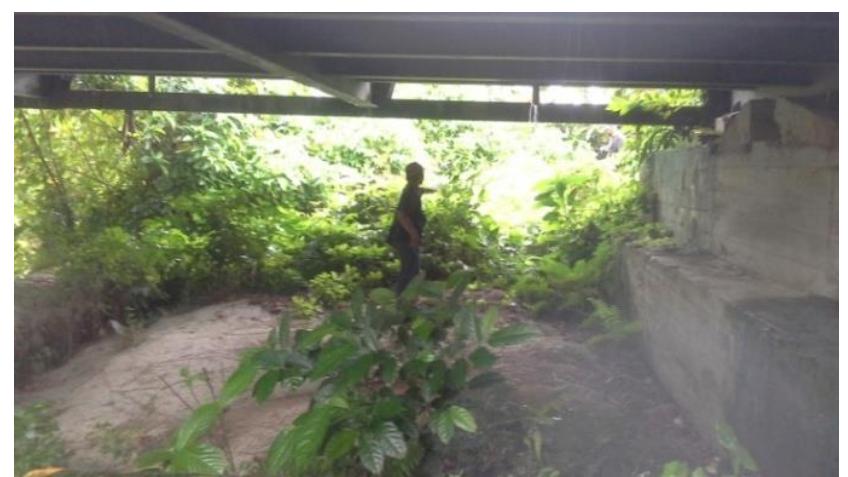

Gambar 14. Tumbuhan Liar pada Abutment Jembatan Idano Mo'awu

Bangunan abutment atau kepala jembatan dalam kondisi yang cukup baik namun perlu adanya pembersihan dari sampah dan tumbuhan liar yang banyak tumbuh di sekitar tebing sungai dan abutment di kedua sisinya yang terlihat pada Gambar 14 .

\subsubsection{Inspeksi Daerah Aliran Sungai (DAS)}

Pada Gambar 15 terlihat aliran air Jembatan dano Gewa sungai cukup tenang dan ada endapan cukup banyak di badan sungai maka diperlukan pengerukan atau normalisasi sungai. kerusakan tersebut termasuk kerusakan berat karena endapan mengurangi $>20 \%$ aliran sungai. 


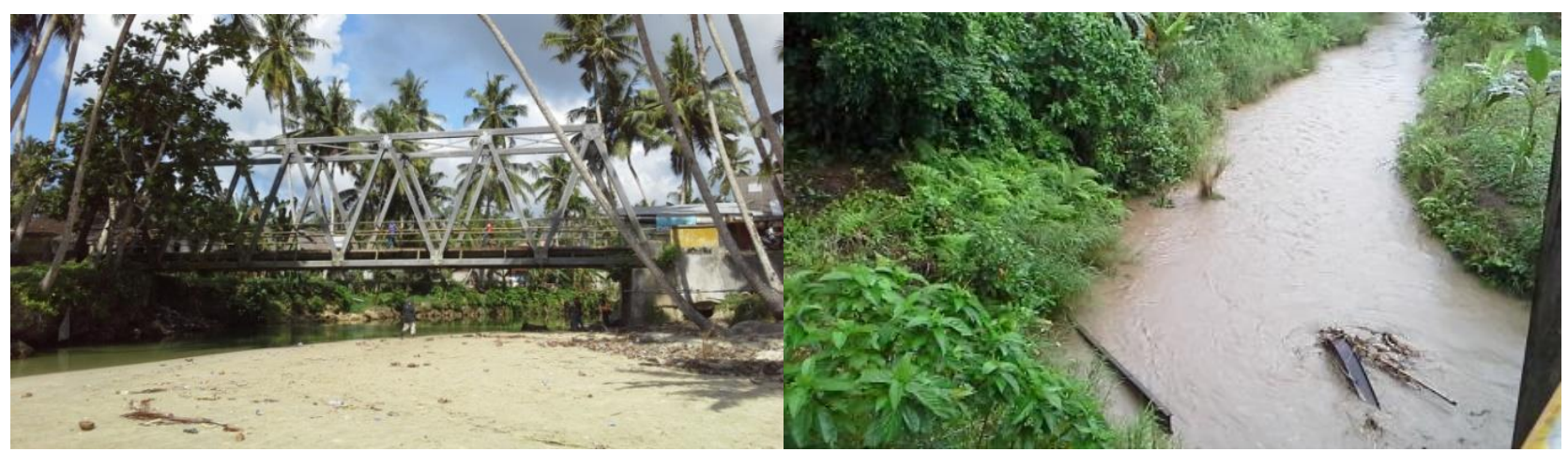

Gambar 15 Endapan pada Aliran Sungai Jembatan Idano Gewa dan Sampah pada DAS Jembatan Idano Mezawa

Terjadinya Hambatan aliran sungai pada Jembatan Idano Mezawa cukup deras saat hujan turun dan aliran sungai berbelok pada arah hilirnya yang terdapat endapan yang hampir berupa daratan terlihat pada Gambar 15. Pada sisi hulunya terdapat sampah berupa sisa bangunan jembatan (baja IWF) yang jika tidak segera dibersihkan khawatir akan menghambat aliran sungai.

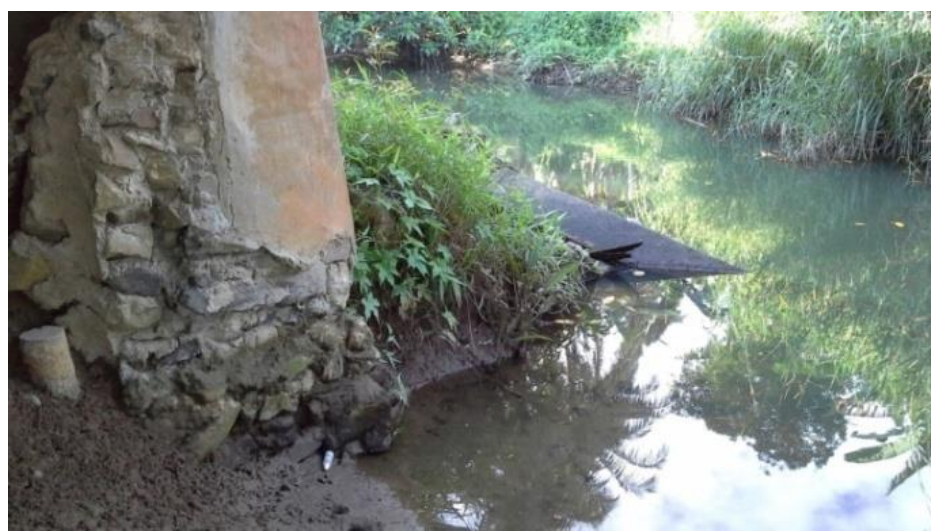

Gambar 16. Gabion yang Sudah Hilang di Bagian Bawah Jembatan Hili Gelo Sekitar Abutment

Perlindungan terhadap aliran sungai berupa gabion sudah hilang di bagian bawah jembatan sekitar abutment terlihat pada Gambar 16. Tetapi masih ada di bagian hulu dan hilir jembatan. Pemasangan gabion di kaki abutment untuk melindungi abutment dari penggerusan akibat aliran sungai. Kerusakan yang terjadi hanya kerusakan ringan karena tidak terjadinya pengikisan dasar sungai

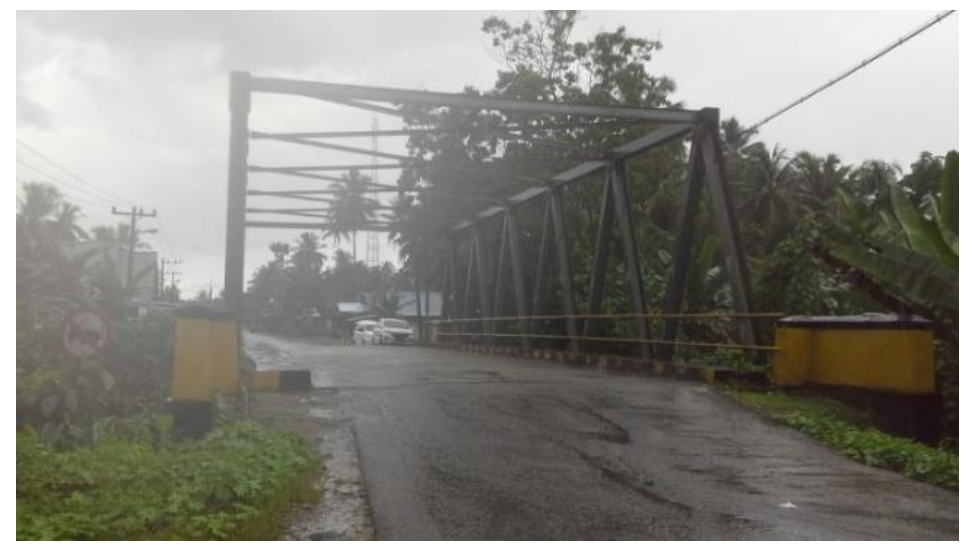

Gambar 17. Penurunan Timbunan Jalan Pendekat Jembatan Idano Mo’awu

Lantai jembatan yang terlalu tinggi sehingga adanya beda elevasi antara oprit dan lantai jembatan yang dapat mengurangi kenyamanan berkendara dan keamanan ketahanan terhadap struktur. Pada gambar 17 terlihat Ada kelandaian pada oprit dan beda elevasi ini menyebabkan lompatan kendaraan dari sisi Gunung Sitoli. Perlu dilakukannya overlay permukaan jembatan. Karena overlay yang dilakukan hanya badan jalan sehingga terjadi beda elevasi. Overlay dilakukan dari oprit awal hingga oprit akhir. Kerusakan ringan karena permukaan di bawah ketinggian fondasi

Hasil penelitian dari inspeksi jembatan di pulau Nias maka diperoleh nilai kondisi existing terhadap 10 jembatan yang merupakan objek penelitian yang dirangkum dalam bentuk Tabel 3 berikut ini. 
Tabel 3 Nilai Kondisi Jembatan Pulau Nias Provinsi Sumatera Utara

\begin{tabular}{lllcccc}
\hline & & \multicolumn{3}{c}{ Kondisi Umum Jembatan } \\
\cline { 3 - 6 } No & Nama Jembatan & $\begin{array}{c}\text { Bangunan } \\
\text { Atas }\end{array}$ & Lantai & $\begin{array}{c}\text { Bangunan } \\
\text { Bawah }\end{array}$ & $\begin{array}{c}\text { Daerah Aliran } \\
\text { Sungai }\end{array}$ & Jembatan \\
\hline 1 & Idano Gido Sebua & 2 & 1 & 4 & 0 & 4 \\
2 & Idano Matuho & 5 & 5 & 5 & 1 & 5 \\
3 & Idano O'ou & 2 & 4 & 1 & 2 & 4 \\
4 & Idano La'uri & 2 & 2 & 3 & 0 & 4 \\
5 & Idano Hili Geho & 4 & 4 & 3 & 3 & 3 \\
6 & Idano Bowongahono & 3 & 3 & 2 & 2 & 4 \\
7 & Idano Gewa & 3 & 4 & 3 & 2 & 2 \\
8 & Idano Susua & 1 & 2 & 1 & 2 & 4 \\
9 & Idano Mezawa & 1 & 1 & 4 & 3 & 1 \\
\hline 10 & Idano Mo'awu & 1 & 1 & 1 & & 4 \\
\hline
\end{tabular}

Dari hasil penilaian kondisi jembatan beserta komponennya terhadap 10 jembatan di pulau Nias provinsi Sumatera Utara diperoleh nilai kondisi masing-masing jembatan. Terdapat kerusakan pada beberapa jembatan yang pada umumnya terdiri dari kerusakan permukaan perkerasan jalan, elemen struktur utama jembatan, bangunan pelengkap jembatan, dan daerah aliran sungai. Kerusakan pada jembatan dapat ditangani dengan beberapa metode yang disesuaikan dengan jenis dan dimensi kerusakannya. Selain perlu ada penanganan terhadap kondisi elemen jembatan yang mengalami kerusakan, perlu diperhatikan juga penyebab kerusakan tersebut antara lain metode konstruksi, kualitas bahan, desain perencanaan, dan lingkungan jembatan. Masalah lain yang terjadi pada jembatan di Pulau Nias, Sumatera Utara ini adalah masalah yang diakibatkan oleh gempa yang pernah terjadi disana. Akibat dari bencana alam tersebut, struktur jembatan mengalami kerusakan dalam kondisi kritis bahkan tidak berfungsi lagi. Elemen jembatan yang kerap mengalami gangguan pasca gempa adalah abutment atau kepala jembatan. Bergesernya atau rusaknya abutment secara struktural dapat memberi efek untuk terjadinya kerusakan pada elemen lain yang dapat memperburuk kondisi jembatan jika tidak segera ditangani. Maka dari itu, perbaikan atau rehabilitasi perlu segera dilakukan pada jembatan yang memiliki kondisi kritis. Untuk jembatan yang masih dapat berfungsi dengan layak dan aman, perlu perawatan dan pemeliharaan terhadap bangunan jembatan dan daerah aliran sungai sehingga terciptanya fungsi jembatan dan daerah aliran sungai yang sesuai dengan rencana desainnya. Perbaikan, perawatan dan pemeliharaan dilakukan berdasarkan skala prioritas penilaian kondisi jembatan.

\subsection{Penanganan Perbaikan Kerusakan Jembatan}

\subsubsection{Perbaikan Lapis Permukaan Aspal}

Lapis permukaan yang mengalami retak atau pengelupasan hingga menyebabkan permukaan bergelombang dan berlubang perlu dilakukan penambalan atau pelapisan aspal baru agar kondisi permukaan perkerasan jalan sama rata dengan permukaan perkerasan jalan eksisting.

\subsubsection{Perbaikan Kerusakan Sandaran Jembatan}

Sandaran horizontal dan atau tiang sandaran yang mengalami kerusakan dan atau hilang perlu dilakukan penggantian item tersebut dengan item yang baru

\subsubsection{Perbaikan Sambungan (Siar Muai)}

Pada umumnya, siar atau sambungan jembatan dibuat renggang untuk menyiasati adanya muai pada jembatan. Namun jika siar muai mulai merenggang dan mengganggu kenyamanan pengguna lalu lintas jembatan, maka hal tersebut perlu diselidiki apakah kerenggangan siar diakibatkan adanya pergerakan tanah dasar abutment sehingga abutment bergeser dari sumbunya dan membuat siar merenggang terlalu lebar. Jika kerenggangan siar masih dalam batas keandalannya, maka direkomendasikan untuk mengisi celah siar dengan zat yang bersifat elastis contohnya asphaltic plug binder. 


\subsubsection{Perbaikan Pada Beton Retak}

Jika retak pada beton terjadi maka perlu dilakukan patching atau penambalan beton patching dapat dilakukan untuk mengatasi keretakan beton ringan yang memiliki lebaran retak $<0,3 \mathrm{~mm}$ atau dengan Grouting/injection dapat dilakukan untuk menangani keretakan pada beton dengan lebar keretakan $>0,3 \mathrm{~mm}$ seperti terlihat pada Gambar 18. Penggunaan material BASF yaitu MasterInject 1333 untuk grouting retak dengan penggunaan pelarut epoxy bebas berbasis resin sistem injeksi grouting untuk mengembalikan integritas struktural.

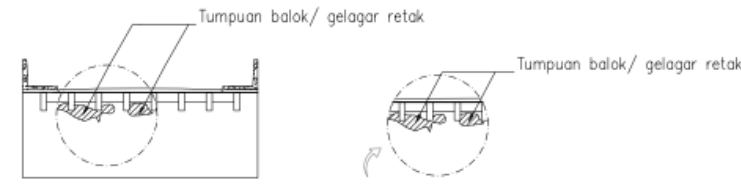

POTONGAN MELINTANG EXISTING
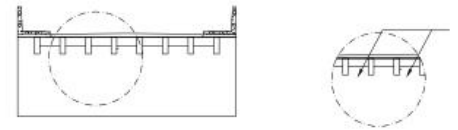

Runtuhkan bagian beton keropos dan Runlunkan bagian beton
patching otou grouting.

\section{POTONGAN MELINTANG}

Gambar 18. Perbaikan Pada Beton Retak

\subsubsection{Perbaikan pada Tulangan dan Rangka Baja yang Korosi}

a. Korosi pada tulangan merupakan reaksi kimia yang berdifusi ke dalam beton sampai ke permukaan besi tulangan yang menyebabkan hilangnya lapisan pasif besi. Korosi menyebabkan berkurangnya diameter tulangan dan membesarnya reaksi korosi. Besarnya reaksi korosi yang terjadi dapat mengakibatkan tertekannya bagian beton di sekeliling tulang terkorosi hingga menyebabkan keretakan dan pengelupasan terutama pada selimut beton.

b. Korosi pada rangka baja utama jembatan mengalami korosi ringan, direkomendasikan untuk memperbaiki bagian terkorosi dengan cara pembersihan korosi dan dilakukan perlindungan terhadap korosi seperti pengecatan. Namun jika terjadi korosi berat pada rangka baja utama, maka perlu dilakukan penggantian rangka baja terkorosi dengan rangka baja baru yang dalam kondisi baik. Pemotongan bagian yang terkorosi dapat dilakukan sebelum proses penggantian dengan bagian yang baik.

c. Ketika baja terlihat dan kedalaman selimut beton kurang dari $10 \mathrm{~mm}$ maka penggunaan material BASF MasterEmaco P 5000 yang merupakan primer aktif, yang mengandung penghambat korosi aktif untuk perlindungan baja tulangan.

\subsubsection{Perbaikan Beton Lapuk}

Pelapukan terjadi akibat faktor lingkungan yang sejalan dengan umur struktur beton. Pelapukan dapat diatasi dengan menggunakan metode chipping dan patching dengan menggunakan material BASF yaitu MasterInject 1333 seperti terlihat pada Gambar 19.

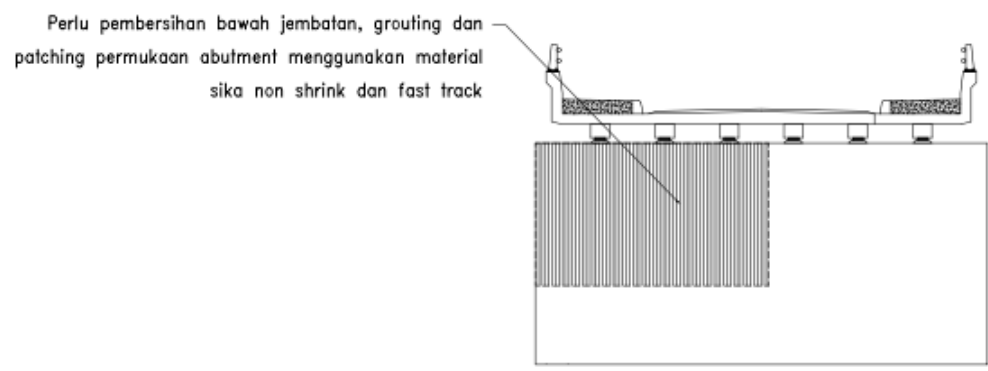

Gambar 19. Perbaikan Beton Lapuk atau Tua

\subsubsection{Perbaikan Lubang Abutment}

Adanya lubang dalam abutment (kepala jembatan) perlu mendapatkan penanganan dini dengan mengisi lubang tersebut dengan masa beton seperti terlihat pada Gambar 20. Jika dibiarkan, maka dikhawatirkan abutmen (kepala jembatan) akan mengalami guling karena berkurangnya berat struktur untuk menahan beban yang abutment pikul.
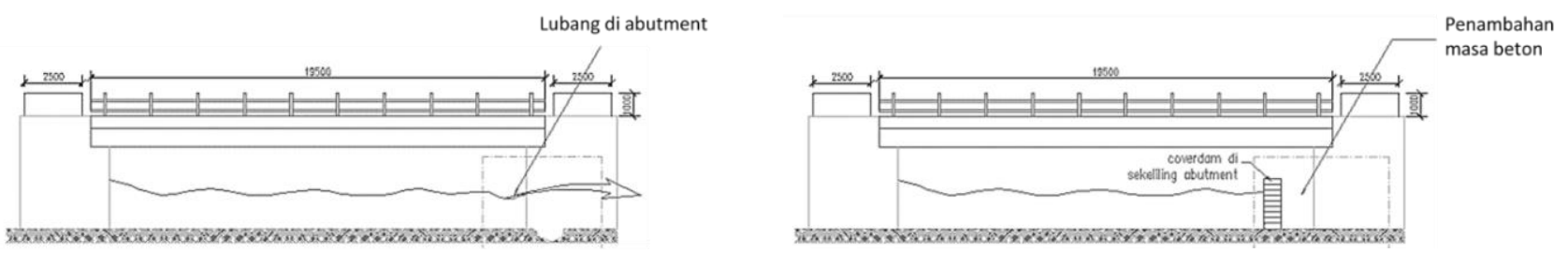

Gambar 20. Perbaikan Lubang Abutmen 


\subsubsection{Perbaikan akibat Scouring/ Penggerusan}

Penggerusan pada abutment terjadi akibat adanya gangguan terhadap aliran air sungai yang menyebabkan arus pusaran yang dapat mengikis bangunan di sekitarnya, termasuk abutment jembatan. Pada abutment yang telah tergerus, perlu diperbaiki dengan beberapa metode penanganan yaitu Penambahan masa beton dan pembuatan bronjong dan Soil nailing seperti terlihat pada Gambar 21.
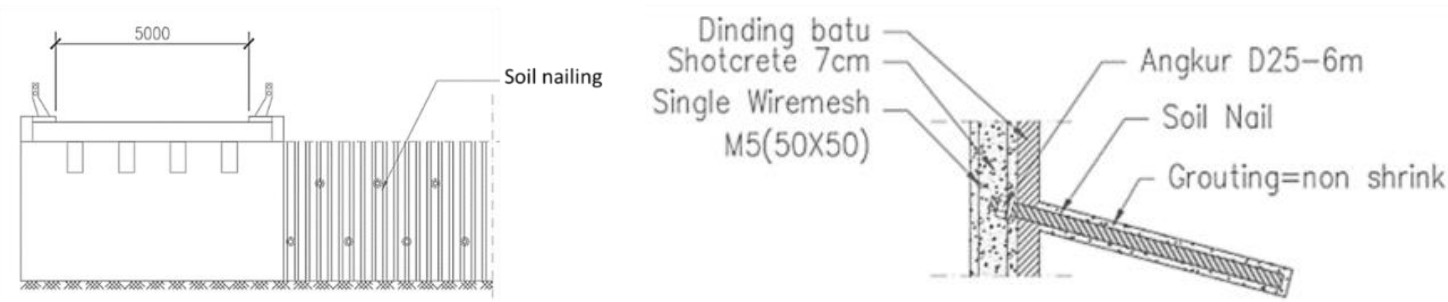

Gambar 21. Soil Nailing

\subsubsection{Pembersihan Endapan di DAS}

Tumpukan sampah dan tanaman liar di tepian sungai Sampah di tepian sungai perlu dibersihkan sehingga tidak menghambat aliran air dan menyebabkan meluapnya air saat debit air meningkat. Sedimentasi dan pendangkalan di sungai Sedimentasi sungai dapat dilakukan dengan normalisasi sungai sehingga aliran dapat kembali lancar dan dilakukan pengerukan rutin untuk mengurangi volume sedimentasi. Jika sedimentasi cukup besar, atau hal tersebut dapat ditangani dengan bangunan sediment trap.

\subsubsection{Perkuatan Dinding / Pilar Pasangan Batu}

a. Pada pilar pasangan batu, pasang angkur yang dibengkokkan di kedua ujungnya dengan salah satu ujungnya ditanam ke dalam pilar pasangan batu eksisting dengan cara melubangi dan shotcrete terlihat pada Gambar 22.

b. Pasangkan tulangan vertikal dan horizontal pada permukaan luar pasangan batu eksisting dengan ukuran D 160-300.

c. Ujung lain angkur diikatkan ke joint tulangan vertikal dan horizontal. Sehingga angkur akan ada di setiap grid $300 \mathrm{~m}$.

d. Beri shotcrete dengan tebal $150 \mathrm{~mm}$.

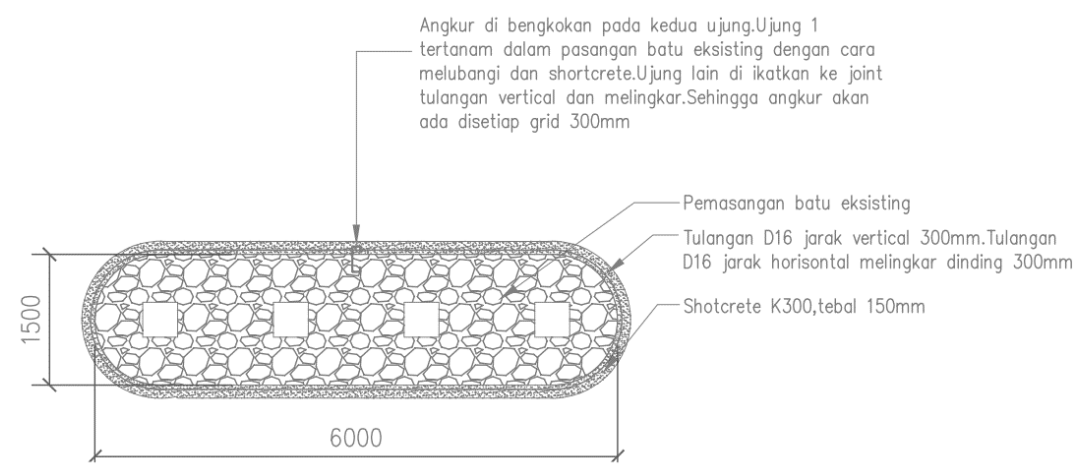

\subsubsection{Pembersihan Tanaman Liar}

Gambar 22. Perkuatan Dinding/ Pilar Pasangan Batu

Perlu pembersihan tanaman liar di sekitar abutment dan elemen struktural lainnya untuk mencegah kerusakan dan pelapukan beton. Pembersihan dapat dilakukan dengan cara manual yaitu dengan penghilangan tanaman liar dari lingkungan struktural seperti terlihat pada Gambar 23.

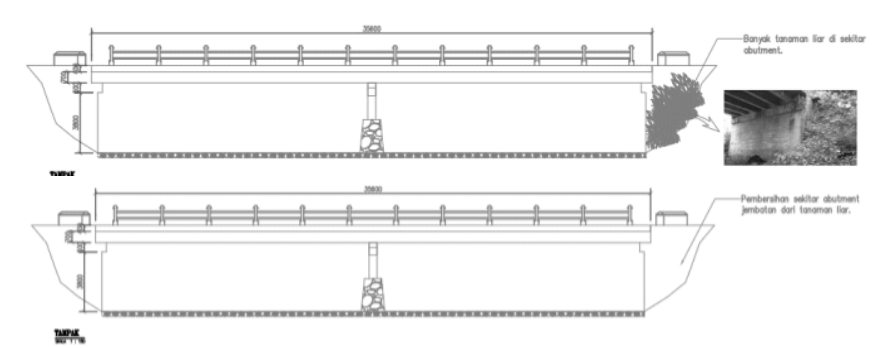

Gambar 23. Pembersihan Tanaman Liar di Elemen Jembatan. 


\subsubsection{Scouring Tebing Sungai dan Pengikisan Dasar Sungai Dekat Pilar atau Abutment}

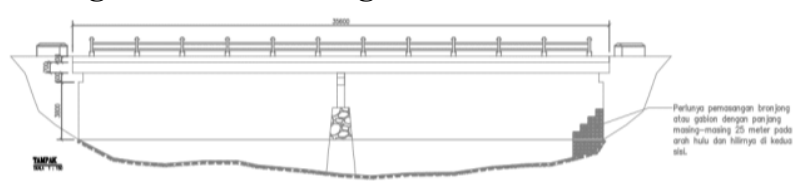

Gambar 24. Pemasangan Bronjong pada Tebing Sungai/Kaki Abutment

a. Penggalian untuk penempatan bronjong sebagai landasan kunci bronjong.

b. Pemasangan bronjong atau gabion dengan panjang masing-masing 25 meter pada arah hulu dan hilirnya di kedua sisi DAS (atau sesuai desain).

c. Dimensi bronjong pada umumnya dipasang dengan lebar $1 \mathrm{~m}$ dan tinggi $0.5 \mathrm{~m}$ atau sesuai dengan perencanaan seperti terlihat pada Gambar 24.

\subsubsection{Perbaikan Retak vertikal pada Gravity Wall}

a. Kenali tipe retakan

b. Jika retakan terjadi akibat penambahan beban berlebih, maka perlu dilakukan pengamatan terlebih dahulu selama 3 bulan terhadap gravity wall tersebut, apakah strukturnya mengalami penurunan atau tidak

c. Jika struktur telah stabil dan tidak mengalami penurunan, maka retakan perlu diberikan penambahan masa pasangan batu agar material oprti tidak keluar dan menjadi longsoran pada oprit.

d. Penambahan masa pasangan batu dapat dilakukan pada bagian yang rusak/ celah retakan atau lakukan wall jacketing untuk melindungi struktur gravity wall secara keseluruhan seperti terlihat pada Gambar 25.

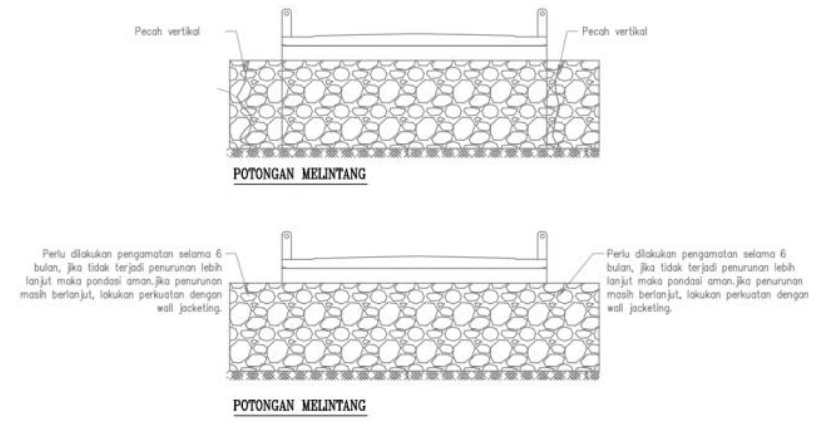

Gambar 25. Perbaikan Retak Vertikal pada Gravity Wall Pasangan Batu

\section{KESIMPULAN}

Nilai kondisi terhadap 10 jembatan di pulau Nias Provinsi Sumatera Utara dengan menggunakan standar Bridge Management System (BMS) 1992 adalah 1 Jembatan kondisi runtuh, 5 jembatan kondisi kritis, 2 jembatan kondisi 3 rusak berat, 1 jembatan kondisi rusak ringan dan 1 jembatan kondisi baik. Dari penilaian beberapa jembatan di pulau Nias provinsi Sumatera Utara memperoleh nilai dari kondisi masing-masing Jembatan Idano Gido Sebua, Jembatan Idano O'ou, Jembatan Idano Hili Geho, Jembatan Idano Gewa, Jembatan Idano Mezawa adalah jembatan paling kritis yang memiliki nilai kritis. Sementara Jembatan Idano Matuho memiliki nilai kondisi rusak berat yang terdiri dari bangunan atas rusak berat, lantai bangunan rusak berat, dan bangunan bagian bawah rusak berat. Dengan dilakukan penilaian terhadap kondisi jembatan dengan Bridge Management System (BMS) 1992 maka dapat ditentukan rekomendasi penanganan dan membuat urutan berdasarkan skala prioritas. Karena metode yang digunakan pada inspeksi kondisi jembatan secara visual maka perlunya dilakukan pemeriksaan lebih lanjut setelah dilakukan pemeriksaan dan penilaian kondisi jembatan agar dapat mengetahui kerusakan-kerusakan pada komponen bagian dalam.

Pada Tabel 4 memperlihatkan rekomendasi penanganan jembatan yang diklasifikasikan menurut skala prioritas penanganannya. Rekomendasi tahun penanganan diurutkan ke dalam 3 (tiga) tahun pertama sejak laporan inspeksi ini selesai. Rekomendasi penanganan jembatan dikategorikan berdasarkan tingkat kerusakannya:

a. Penanganan sementara dilakukan jika elemen jembatan dalam kondisi darurat karena kerusakan mempengaruhi struktur, kenyamanan dan keamanan jembatan

b. Rehabilitasi dilakukan jika kondisi elemen jembatan memerlukan perbaikan struktur dalam skala besar

c. Penggantian dilakukan jika elemen jembatan sudah tidak berfungsi lagi

d. Pemeliharaan rutin dilakukan jika elemen jembatan memerlukan perbaikan atau pemeliharaan dengan sifatnya tidak mengganggu struktur jembatan

e. Pemeriksaan khusus (monitoring) dilakukan jika elemen jembatan memerlukan pengamatan khusus sebagai langkah awal untuk mengambil tindakan perbaikan atau penanganan terhadap gejala kerusakan struktur. 


\begin{tabular}{|c|c|c|c|c|c|c|c|c|c|c|c|c|c|}
\hline \multirow{3}{*}{ NO } & \multirow{3}{*}{ NAMA JEMBATAN } & \multicolumn{12}{|c|}{ REKOMENDASI TAHUN PENANGANAN } \\
\hline & & \multicolumn{4}{|c|}{1} & \multicolumn{4}{|c|}{2} & \multicolumn{4}{|c|}{3} \\
\hline & & LNT & BA & BB & DAS & LNT & $\mathbf{B A}$ & BB & DAS & LNT & $\mathbf{B A}$ & BB & DAS \\
\hline 1 & $\begin{array}{l}\text { Jembatan Idano Gido } \\
\text { Sebua }\end{array}$ & - & - & PK & - & $\mathrm{T}$ & $\mathrm{T}$ & - & - & - & - & - & - \\
\hline 2 & $\begin{array}{l}\text { Jembatan Idano } \\
\text { Matuho }\end{array}$ & DED & DED & DED & - & - & - & - & $\mathrm{T}$ & - & - & - & - \\
\hline 3 & Jembatan Idano O'ou & DED & DED & - & - & - & - & $\mathrm{T}$ & $\mathrm{T}$ & - & - & - & - \\
\hline 4 & Jembatan Idano La'uri & - & - & PK & - & $\mathrm{T}$ & $\mathrm{T}$ & - & - & - & - & - & - \\
\hline 5 & $\begin{array}{l}\text { Jembatan Idano Hili } \\
\text { Geho }\end{array}$ & PK & - & - & PK & $\mathrm{R}$ & $\mathrm{R}$ & $\mathrm{R}$ & $\mathrm{R}$ & - & - & - & - \\
\hline 6 & $\begin{array}{l}\text { Jembatan Idano } \\
\text { Bawonahono }\end{array}$ & - & - & - & - & $\mathrm{R}$ & $\mathrm{R}$ & $\mathrm{R}$ & $\mathrm{T}$ & - & - & - & - \\
\hline 7 & Jembatan Idano Gewa & - & - & - & - & $\mathrm{R}$ & $\mathrm{T}$ & $\mathrm{T}$ & $\mathrm{T}$ & - & - & - & - \\
\hline 8 & Jembatan Idano Susua & - & - & - & - & - & - & - & - & $\mathrm{T}$ & $\mathrm{T}$ & $\mathrm{P}$ & $\mathrm{T}$ \\
\hline 9 & $\begin{array}{l}\text { Jembatan Idano } \\
\text { Mezawa }\end{array}$ & - & - & PK & $\mathrm{T}$ & - & - & - & - & $\mathrm{T}$ & $\mathrm{T}$ & - & - \\
\hline 10 & $\begin{array}{l}\text { Jembatan Idano } \\
\text { Mo'awu }\end{array}$ & - & - & - & - & - & - & - & - & $\mathrm{T}$ & $\mathrm{T}$ & $\mathrm{T}$ & $\mathrm{T}$ \\
\hline
\end{tabular}

Keterangan:

Rekomendasi penanganan jembatan berdasarkan tingkat kerusakannya:

$\mathrm{T} \quad=$ Penanganan Sementara

$\mathrm{R} \quad=$ Rehabilitasi

$\mathrm{G} \quad=$ Penggantian

$\mathrm{P} \quad=$ Pemeliharaan Rutin

PK $\quad=$ Pemeriksaan Khusus (Monitoring)

DED = Perlu pelaksanaannya perencanaan desain lebih lanjut dalam pekerjaan DED

\section{DAFTAR PUSTAKA}

[1] Apriani W., Megaasri SW., Loka WAP., 2018, Penilaian Kondisi Jembatan Rangka Baja Di Riau dengan Metode Bridge Management System, Jurnal Teknik Sipil, Vol. 4, No. 2

[2] Direktorat Jenderal Bina Marga Departement Pekerjaan Umum Republik Indonesia, 1993, Panduan Pemeriksaan Jembatan, Jakarta.

[3] Hasanudin., 2017, Metode Penilaian Kondisi Jembatan Beton Prategang, Jurnal Media Teknik \& Sistem Industri Vol.1 hal.72-81

[4] Hariman F., Christady HH., Triwiyono A., 2007, Evaluasi dan Program Pemeliharaan Jembatan dengan Metode Bridge Management System (BMS), Forum Teknik Sipil No. XVII

[5] Herry Y., Nuh SM., Indrayadi M., 2019, Penilaian Kondisi Jembatan Rangka Baja Di Kabupaten Sintang Menggunakan Metode Bridge Management System (BMS), Jurnal Mahasiswa Teknik Sipil, Vol 6, No 1

[6] Putri CK., Sastrawiria RPP., 2018, Analisis Penerapan Aplikasi Inspeksi Visual Jembatan Invi J (User Perspective), Jurnal Proyek Teknik Sipil, Vol 1 (1), hal 29-37

[7] Yin, Z.H.; Li, Y.F.; Guo, J.; Li, Y. Integration Research and Design of the Bridge Maintenance Management System. Procedia Eng. 2011, 15, 5429-5434

[8] She, T.H.; Sarshar, M. A Geographic Information System (GIS)-Based Bridge Management System. Comput. Civ. Infrastruct. Eng. 1999, 14, 417-427. [CrossRef]

[9] Estes, A.C.; Frangopol, D.M. Updating Bridge Reliability Based on Bridge Management Systems Visual Inspection Results. J. Bridg. Eng. 2003, 8, 374-382. [CrossRef]

[10] Roelfstra, G.; Hajdin, R.; Adey, B.; Brühwiler, E. Condition Evolution in Bridge Management Systems and CorrosionInduced Deterioration. J. Bridg. Eng. 2004, 9, 268-277.

[11] Qi, J.; Issa, R.R.A.; Olbina, S.; Hinze, J. Use of Building Information Modeling in Design to Prevent Construction Worker Falls. J. Comput. Civ. Eng. 2014, 28, A4014008.

[12] Gibb, A.; Haslam, R.; Gyi, D.; Hide, S.; Duff, R. What Causes Accidents? Institution of Civil Engineers: London, UK, 2006; Volume 159, pp. 46-50. 